\title{
導言: 從經典文本到現實議題
}

\author{
張 穎
}

本期論文選自《醫學與哲學》雜誌社和香港浸會大學應用倫理 學研究中心於今年暑期在承德合辦的“第八屆建構中國生命倫理學 研討會”。大多數論文圍繞當今中國醫學倫理學出現的具體問題與 實踐, 從中國生命倫理學與西方生命倫理學的雙重面向探討有關醫 師職業道德、傳統醫術與醫德、醫患關係、器官移植、終極關懷等 諸方面的問題。同時對於這些倫理議題的討論也涉及到對傳統文化 的認識與詮釋的問題。本期選入的論文從不同的議題回應建構中國 生命倫理學的可能性與現實性。

構建中國生命倫理學離不開對經典的詮釋。然而從另一方面來 講, 對文本的解讀又會受到讀者當下的個人經驗與興趣的影響。我 們今天談論的一些有關生命倫理學的議題, 特別是那些由於現代科 技所引發的道德爭議, 或者來自西方某些現代倫理或法律概念而並 非經典本身所涉及的。然而這些並不影響我們回到傳統的文本, 與 它們對話與交流, 並持續不斷地探究。譬如, 如何從儒家的傳統看 待守護自己的身體? 本期有兩篇論文都與這個話題有關，但關注的 角度有所不同。

在本期首篇論文中, 方耀對身體的解讀始於作為儒家經典文本 《孝經》中一句名言, 即“身體發膚, 受之父母, 不敢毀傷, 孝之 始也。”由此作者發問：儒家的身體觀與當代社會所倡導的器官捐 獻是否相悖? 文章指出, 在中國生命倫理學界, 學者長期以來把這 句話看作是中國人抗拒遺體或活體器官捐獻的一個重要原因, 並出

張 穎, 香港浸會大學應用倫理學研究中心研究員、宗教及哲學系副教授, 中國香港。 
現所謂的 “儒家倫理妨礙説”。然而作者拒絕這種傳統的解釋 ; 他 通過文字考據，對 “毀傷”一詞作出不同的詮釋，即“毀傷”亦可 作 “刑傷” 解。

作者認為，醫學倫理學界對 “毀傷” 的片面理解，導致一些學 者誤讀身體在儒家倫理關係中的絕對命令或最高原則, 並由此導致 將《孝經》中的一句話與器官捐獻對立起來。某種程度上可以説， 學者們挖出的是自己埋下的屍體, 攻擊的是自己豎起來的靶子。中 國醫學倫理學界的諸多學者在將 “不敢毀傷”作為妨礙器官捐獻的 觀念來對待時，片面強調了它的負面作用，無視這一觀念的歷史合 理性及對當今社會的正面價值。方耀進一步指出, 欲推動中國的器 官捐獻，將儒家倫理作為對立面予以否定的做法注定是南轅北輬， 生命倫理學界真正應當做的，是論證器官捐獻符合 “立身行道” 乃 至成仁取義，即為了挽救他人生命是可以犧牲身體完整性的，捐獻 器官是為了挽救他人生命，仁者愛人。文章作者認為，儒家在 “不 敢毀傷” 與 “成仁取義” 的道德抉擇之間, 毫無疑問要視後者高於 前者。

葉敬德的〈儒家家庭價值的應用與生物科技倫理〉一文同樣涉 及儒家關於身體與孝道的關係。文章指出, 儒家相信孝道是最重要 的德行。而盡孝的其中一個表現便是守護自己的身體和德行。作者 從宋明理學的觀點，認為儒家把父母看作天地的代理人，把自己的 軀體生命看作是父母血脈之延續。因而行孝被看作是天地之理，守 護身體和德行是行孝的具體表現。文章引用王夫之《四書訓義》中 的一段話來説明這一點：“凡父母而存之日，無非念子之情也。其 所切切然不舍於懷者，唯子之疾也……但於此而念之：父母之（愛 我）也如此，而我即何以酬之乎？父母之憂我也如此，而我將何以 慰之乎？……以此思事親、以此思守身, 戰戰慄慄, 無忘於夙夜, 而敢侈言孝乎？”（王夫之，1990，289-290）

這裏，我們遇到如何理解儒家傳統中 “守身”與 “捨身” 的關 係。就孔孟之道而言, 孔子有 “成仁”之論, 孟子有 “取義”之見。 
兩者都涉及到人“求生”和“害仁”在“生”與“義”之間發生衝 突時能否做出道德選擇。“守身” 是就一般狀況而言, 強調人要愛 惜生命，保全身體。同時，孔子以“全乎心而忘乎身，全乎身而忘 乎世”（王夫之，1990，452）指出君子不因己身困厄而撓其心，亦 不因世俗毀譽而動其志。由此可見, 孔子把 “成仁” 看作高於一切。 那麼 “孝”與 “仁” 的關係是什麼？當問到 “孝弟為仁之本，此是 由孝弟可以至仁否? ”這一問題時, 程匵回答道：“非也。謂行仁 自孝弟始, 孝弟是仁之一事, 謂之行仁之本可, 謂是仁之本則不可。 蓋仁是性也, 孝弟是用也。性中有個仁、義、禮、智四者而已，曷 嘗有孝弟來? 然仁主於愛, 愛莫大於尊親, 故曰孝弟也者, 其為仁 之本與! ”（程影、程頤，2004，183）換言之, 孝弟在行仁, 是仁 者以孝弟行, 但不能説孝弟即為仁。畢竟仁主於愛, 愛有其廣泛性, 孝弟雖是愛的具體表現, 並不表示孝弟即為更為寬泛的愛, 因此, 知孝弟只是仁之一舉, 其合於仁之性, 也非仁的主體。從另一方面 講，宋儒所説的天地父母可以看作是強調 “下學人事”、“上達天 道”, 而非一定是將父母等同於天地。由此可見, 《四書訓義》承 繼宋儒的傳統，認為 “仁”的關鍵在於人的體驗與實踐。

那麼，我們如何看待 “守身” 與 “捨身” 與器官捐獻的關係? 毫無疑問, 器官移植是近代醫學科技發展的產物, 並由此引發了種 種的倫理爭論。器官捐獻亦是當今生命倫理學所面臨的一個實際問 題。隨着科技的發展, 當代社會亦出現新的道德議題。因此, 當代 生命倫理學者嘗試從不同的宗教、哲學和文化傳統回應新時代議題 的挑戰。葉敬德的文章引出了一個主要問題, 即我們所説的傳統是 什麼：只是經典還是仍在延續的活的經驗(lived experience) ? 作者認 為, 部分學者在詮釋儒家傳統時, 往往只是選取某些儒家的重要概 念, 或引用某些儒家重要的經典, 然後論證儒家如何回應某議題。 然而, 儒家並非只是一套哲學的系統, 因為在過往千多年, 作為活 的傳統, 儒家一直為中國人社會提供具體生活的指導原則。因此, 真正的問題是當我們將這些原則應用到今天所處理的類同議題時, 
將會出現怎樣的狀況。換言之, 儒家原則在歷史上的實際應用是否 可以為當代建構儒家倫理提供在概念與經典之外的文化資源。這是 關乎於建構儒家倫理的方法問題, 回答這個問題, 我們需要研究中 國的醫學史, 尤其是那些與儒醫行醫活動相關的歷史。也就是葉文 所指出的，我們在試圖解釋經典中的某個概念或思想時，應該注意 這些概念和思想在當時的具體歷史情境中是如何具體應用的。當 然，中國文化傳統從來都不是單一的，除了儒家傳統之外，還有道 家和佛家。譬如，《列子》有“生相憐，死相捐”的説法，道家的 自然主義的態度不強調對死者感情上的留戀和執着，這一點在《莊 子》中表現得更為顯著。佛教傳入中土之後, 其特有的生死觀對傳 統儒家身體觀帶來了強烈的衝擊, 如火葬的風俗以及捨身佈施的菩 薩精神。

在〈“儒醫”概念的文化與政治意藴〉一文中，作者程國斌恰 恰是通過對宋、明時期醫史資料的研究，以歷史的流變系統地論述 中國傳統醫學與倫理學和政治學之間的關係。論文對《宋會要輯稿》 所輯錄北宋官方文件中 “儒醫”一詞的前後語境及相關政策設計思 路進行了考查, 認為北宋官方提出 “儒醫” 概念, 是在醫學社會發 展需要和醫學社會地位低下的雙重壓力下所採取的政策選擇, 其主 要目的是通過官方的制度設計和 “文化正名” 的方式吸引儒生加入 行醫的職業, 並以此加強醫學行業, 同時也可借此將醫學更好地統 一於王政之大體系之中。作者指出, 雖然在中國歷史上儒者知醫是 比較普遍的現象，但到了北宋時期 “儒醫” 這一詞語才正式出現， 儒醫作為一個社會群體更是要等到南宋之後才被廣泛認可。宋代以 後 “醫儒合流” 的思想努力，使儒學價值話語成為醫學評價的標 準, “儒醫”更成為醫家最重要的評判標準。

那麼“儒醫”的特殊性在哪裏? 是學者、政治家還是專業人 士 ? 或是 “儒醫” 賦予了醫師獨有的價值取向? 儒家的心性修養理 論與中醫理論之間的關係是什麼? 文章引用了明人蕭京《軒岐救正 論·卷之六》中對儒醫的定義：“嘗稽秦漢以後，有通經博史，修 
身慎行, 聞人碩儒, 兼通乎醫者, 精究玄機, 洞明至道”。（蕭京， 1983，511）這裏，“儒醫”被描述為“通才之士”。根據蕭京的定 義, “儒醫”具備三個特徵：(一) 精通醫經、醫理; (二) 善於用儒學 的方法理解和運用醫學經典; (三) 明確醫者的道德定位。其實, “儒 醫” 與一般醫師的區別在於他們是以儒家思想指導行醫活動, 是否 具有明確的儒生身份並不重要。值得注意的是, 宋代的醫師比附佛、 道的宗教傳統, 這一點在歷史文獻有不少記載, 但由於受論文篇幅 的局限，程國斌的文章沒有具體將 “儒醫”與同時代的 “佛醫”、 “道醫” 或其他醫師做比較, 並説明他們之間的關係。“三教合一” 的説法宋明以後十分流行, 值得關注三教在醫學中的體現。

另外，文章提到 “儒醫” 最為一個社會群體的問題。那麼 “儒 醫” 是否具有獨立的社會身份，擁有自主的行會呢？作者認為，傳 統中國的 “儒醫”缺乏具體的法律或制度上的資格限制與邊界，不 得不擺蕩在社會聲望的標籤和具體的社會群體之間。也就是説, “儒 醫” 的身份並沒有從社會意義上縮小他們與 “土者” 的社會鴻溝。 但從另一角度而言，宋代流行的官方醫學教育又將 “儒醫” 納入正 統的體制 (興建太醫學) 之中。如此一來, “儒醫”除了一般的行 醫活動之外, 還承擔了為皇權服務的責任。作者最後的結論是, 沒 有皇權的特意扶持和文化正名，“醫儒合流”不一定成為社會的主 流。

本刊另一篇論文不但與經典文本有關，也與儒道合流有關。張 巧霞〈醫學倫理思想在《聖濟經》中的體現〉一文所探討的對象是 宋代中醫理論的奠基之作一《聖濟經》。根據傳統, 宋代的《聖 濟經》 (10 卷, 分 42 篇, 注重醫學理論) 同《政和聖濟總錄》 (亦稱 《聖濟總錄》，醫學百科，200 卷，分 66 門，闡述病因、病理及醫 治藥方) 都是由宋徽宗趙佶(1082-1135) 親自主持編纂的醫學大作， 前者出版於 1118 , 後者出版於 1122 。正如《政和聖濟總錄》序言： “生者天地之大德, 疾者有生之大患, 方術者治疾之大法”。《聖 
濟經》和《聖濟總錄》無疑成為中國醫學史上不可忽視的醫學經典。 (林昭庚，2000)

正如文章所述，由於北宋校正醫書局刊印醫書，對於各科臨床 及傷寒學研究的專著增多, 都反映了一定歷史時代的背景和各自特 點，宋代醫學的發展還表現在醫學教育的發展，疾病診斷水準的提 高, 以及臨床各科的進步。在這種背景下, 《聖濟經》的出現和流 行便不是一個偶然的歷史事件。如果説《黃帝內經》偏重於理論建 設，對病證論述相對較少，那麼《聖濟經》，尤其是《聖濟總錄》 對《內經》所涉病證進行了大量的補充與發揮, 包括病因病理以及 症狀、治法。同時, 《聖濟經》合儒道為一體, 如由陰陽五行發展 出來的儒家綱常人倫, 由氣論發展出來的 “天人相應” 生命哲學和 道家的 “樂生”思想。作者認為, 《聖濟經》的整體觀與辯證觀對 我們理解生命本身以及人倫關係（如夫婦、母親與胎兒）皆有重要 的意義。與此同時，《聖濟經》也吸收了其他學派的思想。

值得注意的是, 由於道家/道教的影響, 兩宋時期的士大夫階層 對宇宙起源、人的精神(理)和物質（氣）的依存關係等哲學議題極為 關注, 從周敦頤、程影、程頣、張載到朱喜各自提出有關義理性命 的論説, 為宋儒形而上學的構成提供了理論的基礎。與此同時, 自 宋以來, 歷朝皇帝都崇信道教。譬如宋太祖纂修《開寶重定之本草》 吸納道士馬志參加。宋太宗纂修《太平聖惠方》，主撰者王懷隱也 曾是一位道士。至於宋徽宗, 更是崇信道教, 並自封 “教主道君皇 帝”。在這樣的歷史背景下，《聖濟經》和《聖濟總錄》涉及到醫 學倫理學的問題（參見林昭庚，2000，第 7 章）。《聖濟經》所體 現的醫學倫理思想，正如張巧霞的文章所闡述的，反映了兩宋時期 儒道合流。《聖濟經》承襲發展了《黃帝內經》辯證觀的因人因地 因時的三因制宜倫理觀，對具體病症進行具體分析，因症施治，形 成自己的辯證思想。

本期另一篇論文探討當代中國醫師的職業道德。劉雲章的文章 〈從儒家傳統論中醫職業精神的形成機制〉，對當代中國醫師的職 
業精神建設作了現實思考。作者認為，儒家的人本文化特質為醫學、 醫療實踐與醫師職業精神營造出獨特的文化背景。儒家的“不為良 相，當為良醫” 的價值觀在歷史上提升了醫學與醫師職業精神的社 會地位與價值。儒家的核心價值思想——仁” 更為深刻地揭示了 醫師職業精神的內在本質與要求。儒家的責任倫理使醫師在行醫實 踐中始終按照社會對醫師職業的整體責任要求、按照為病家謀幸福 的個體責任要求規範自己的言行，儒家的“修身”促進了醫師職業 精神的養成。文章指出, 儒家思想對中國傳統醫師職業精神的形成 為當下中國醫師職業精神建設提供了有益的啟示與借鑒。

劉雲章的論文提出一個有意思的問題：什麼是職業道德或職業 精神? 現代社會所説的職業道德(professional ethics)產生於現代社會 的細化分工。所謂的職業道德或是職業精神, 即人們在進行職業活 動過程中, 一切符合職業要求的心理意識、行為準則和行為規範的 標準。職業道德的目的是調整職業個人、職業主體和社會成員之間 關係的行為準則和行為規範。職業道德的特徵包括考量其職業的特 性、標準的規範性和操作的實際性。另外, 從社會學的角度, 職業 道德也包括其他幾個特徵 : 如群體的共同身份; 相似的教育和專業 培訓背景; 專業知識和技能; 與專業相關的判斷能力; 共用某種價 值取向; 對違規者的相應懲罰機制等等。劉雲章的論文中提到韋伯 (Max Weber) “責任倫理” 這概念, 其實就是現代職業倫理的一個主 要組成部分。作者指出, 在中國醫學史上, 《黃帝內經》較早的記 述了醫師的職業責任。

前面談及的〈“儒醫” 〉一文實際上已經涉及職業道德或是職 業精神的議題。在中國傳統文化中，醫師的醫術本來屬於方技，但 “儒醫”重新明確醫者的道德定位, 將方技與道德結合起來, 使得 “儒醫”共用同一個價值體系, 並且生出了群體的共同身份認同。 但如〈“儒醫” 一文所述，“儒醫”沒有成為真正意義上的獨立 的職業與獨立的身份，因此 “儒醫” 職業精神的定義並不是很清 晰。劉雲章的論文也論述了中國的“儒醫”傳統, 認為醫師“醫人” 
與士大夫 “醫國” 具有相同的道德要求。“醫乃仁術”正是這個思 想的具體體現。反觀當今社會，我們已經沒有作為社會群體的 “儒 士”，因此也沒有傳統中的“儒醫”。但這不意味着當代醫師不可 以借鑒儒家的道德觀, 特別是儒家有關 “良醫” 和 “仁術” 的思想。 談到職業道德或者職業精神, 除了對醫師道德要求之外, 我們 也應該重視職業健康與安全的問題。近些年西方社會在論述職業道 德時, 往往把職業健康與安全(occupational health and safety, 簡稱 OHS) 加進去。想想近幾年中國的醫患矛盾, 想想有多少醫務工作者每天 在焦慮中工作, 職業健康與安全絕不是一件小事。職業道德或者職 業精神是需要的，但同時也應避免“泛道德主義”的空談。

本文最後一篇論文〈德性倫理與醫療專業精神〉也是探討職業 道德的話題。作者陳強立將當代中國醫學倫理學這個話題置於德性 倫理(virtue ethics) 的框架進行審視。文章首先介紹近年一些學者的共 識，他們認為中國醫療行業面臨兩個問題：一是體制不健全；二是 從業人員缺乏專業精神。“中國的醫療體制問題主要是一個市場制 度和政府沒有管理好這個市場的問題。但是, 只要細心分析他們的 説法, 我們不難發現, 中國的醫療體制問題還涉及到醫療行業的道 德操守問題, 用香港人的説法這是涉及到醫療行業人員的專業失德 問題。”陳強立指出, 良好的醫療制度和它的專業精神是不能分割 的。沒有良好的制度，醫療行業人員無法發揮他們的專業精神; 但 是, 倘若醫療行業人員缺乏專業精神, 那麼再好的制度也是徒然。 正如孟子所説：“徒善不足以為政, 徒法不能以自行。” (《孟子. 離婁上》)

制度與德性實際上關乎法律與道德、體制與個人的關係。良好 的制度設計，無疑有利於個人的才能發揮和德性培養。按照麥金泰 爾(Alasdair MacIntyre) 的説法, “德性的道德” (morality of virtues) 與 “規則性的道德” (morality of rules) 不同, 前者注重道德主體的品格 (character), 後者注重道德行為的規範和原則(principle)。二者都具備 “引導” 的功能, 但重心不一樣。作者指出, 生命倫理學中較為流 
行的 “四原則”屬於規則性的道德，然而這種道德就 “醫德”的角 度來看是有問題的：1. 一個醫療行為合理與否往往取決於我們能作 出恰當的道德考慮, 但是恰當的道德考慮並沒有既定的公式, 更多 的是受我們的品格影響；2. “醫德”是道德生活的一環，合理的道德 生活並不能化約為遵守道德守則的生活，正如 “好學生” 不能僅僅 是不違反校規、“好的文章”並不能僅僅是合乎文法規則的句子組 合一樣；3. 倫理學的根本問題是：我們應該如何生活? 我們為什麼 應該如此生活? 它們是每一個人必須思考的問題。顯然，“德性的 道德” 要比 “規則性的道德” 的槓桿要高, 道德的重心也從外在轉 向內在。“德性的道德”不僅僅考慮當下做什麼是對的，還要考慮 什麼是善的, 什麼是美好的人生。這樣的思維方式恰恰是儒家道德 體系的重要特徵。

總之，建構中國生命倫理學，面對中國醫療改革中的種種社會 問題, 我們既需要學習西方的經驗, 也需要瞭解我們自己的文化資 源。經典文本以及歷史文獻或許不可為我們當下的道德議題提供現 成的標準答案，但可提供不同的視角。作為一個學科，生命倫理學 永遠是開放的體系, 因為我們將不斷面臨新的挑戰。此次承德的暑 期學術研討會，學者們正是秉承這樣的一種姿態。

\section{參考文獻}

王夫之：《四書訓義》, 卷十（論語）, 載船山全書編輯委員會編校：《船 山全書》(第七冊)。長沙, 該麓書社, 1990。WANG Fuzhi. Explanatory Notes on the Four Books, vol. 10 (The Analects), in The Completed Works of Wang Chuanshan [Wang Fuzhi], vol. 7, edited by the Editorial Committee of The Completed Works of Wang Chuanshan (Changshi: Yuelu Book House, 1990).

林昭庚：〈兩宋時期醫學〉, 載李經緯、林昭庚主編：《中國醫學通史》, 第七章, 北京：人民衞生出版社，2000。 LIN Zhaogeng. “Chinese Medicine in the Northern and Southern Song Dynasties," in A General History of Chinese Medicine, chapter 7, edited by LI Jingwei and LIN Zhaogeng (Beijing: People's Medical Publishing House, 2000).

程 影、程 頣：《河南程氏遺書》卷第十八, 載王孝魚點校 : 《二程 集》（上）, 北京, 中華書局, $2004 \circ$ CHENG Hao and CHENG Yi. The Extant Works of the Cheng (Brothers) from Henan, chapter 18, in 
Collection of the Cheng Brothers, vol. 1, punctuated edition by WANG Xiaoyu (Beijing: Zhonghua Book Company, 2004).

蕭京: 《軒岐救正論》, 北京: 中醫研究院圖書館藏清刊本影印本, 中醫 古籍出版社, 1983 ○ XIAO Jing. A Discourse on Xuan's and Qi's [Xuan Yuan and Qi Bo] Theories and Treatment of Chinese Medicine (Beijing: Publishing House of Ancient Chinese Medical Books, 1983).

MacIntyre, Alasdair C. After Virtue: A Study in Moral Theory, $2^{\text {nd }}$ edition. (Notre Dame, IN: University of Notre Dame Press, 1984). 